\title{
15 A QUALIDADE DE VIDA PARA MOTORISTAS DE ÔNIBUS: ENTRE A SAÚDE E O TRABALHO1
}

\author{
| Vanessa de Alcantara ${ }^{1}$; Rose Silva² ${ }^{2}$ Eliane Pereira ${ }^{3} ;$ Marcos Andrade Silva $^{4} \mid$
}

\section{RESUMO}

CONTEXTO: O trabalho do motorista de ônibus exige habilidade técnica e controle emocional. É importante a equalização das necessidades de deslocamento da população e a saúde mental do motorista, que está submetido ao humor dos passageiros.

OBJETIVO: Descrever, sob a luz do referencial fenomenológico de Maurice Merleau Ponty, o significado de qualidade de vida para os motoristas de ônibus e sua contribuição para a saúde mental destes trabalhadores.

METODOLOGIA: Estudo do tipo descritivo. Participaram 16 motoristas de ônibus. Dados coletados por entrevista fenomenológica com um roteiro semiestruturado com três perguntas abertas, no período de abril a novembro de 2014. A pergunta explorada foi:"para você o que é qualidade de vida?". Os motoristas de ônibus responderam as questões no próprio roteiro de entrevistas e a análise dos dados obedeceu ao método fenomenológico, considerando quatro passos: suspender, intuir, analisar e descrever. Estudo aprovado pelo Comitê de Ética UFF/ HUAP n ${ }^{\circ}$ 506/339.

RESULTADOS: Para os motoristas de ônibus, a qualidade de vida foi ameaçada pela insatisfação quanto à condição ergonômica dos ônibus em que trabalham e é influenciada pela percepção de valorização profissional mediante melhores salários.

CONCLUSÕES: A qualidade de vida depende de fatores internos e externos. Questões familiares estão diretamente ligadas ao bem-estar do profissional no trabalho. A melhoria apontada é o início de um diálogo entre o trabalhador e a organização, pois a relação de trabalho não é de rivalidade, mas de parceria.

PALAVRAS-CHAVE: Consciência; Percepção; Promoção da saúde

\section{RESUMEN}

"La calidad de vida de los conductores de autobús: Entre salud y trabajo"

CONTEXTO: El trabajo del conductor de autobús requiere habilidad técnica y control emocional. Es importante igualar las necesidades de desplazamiento de la población y la salud mental del conductor que está sometido al estado de ánimo de los pasajeros.

OBJETIVO: Describir a la luz de fenomenológica referencial de Maurice Merleau Ponty el significado de calidad de vida para los conductores de autobús y su contribución a la salud mental de estos trabajadores.

METODOLOGÍA: Estudio descriptivo, con la participación de 16 conductores de autobús. Datos recogidos por medio de la entrevista fenomenológica y un guión con tres preguntas abiertas semi-estructuradas entre abril y noviembre de 2014. La pregunta explorada fue: ¿Qué significa calidad de vida para usted? Los conductores de autobús respondieron a las preguntas directamente en su propio guión de entrevistas y el análisis de datos siguió el método fenomenológico considerando cuatro pasos: suspender, intuir, analizar y describir. Estudio aprobado por el Comité de ética de FFU/Huapi n ${ }^{\circ}$ 506/339.

RESULTADOS: La calidad de vida de los conductores de autobuses fue amenazada por el descontento respecto a la condición ergonómica del autobús que trabajan y fue influenciada por la percepción de valoración profesional a través de salarios más elevados.

CONCLUSIONES: La calidad de vida depende de factores internos y externos. Cuestiones familiares están directamente relacionadas al bien estar del profesional en el trabajo. Las mejorías identificadas son el inicio de un diálogo entre el empleado y la organización, ya que la relación de trabajo no implica rivalidad, sino de asociación.

\section{DESCRIPTORES: Conciencia; Percepción; Promoción de la} salud

\begin{abstract}
"Life quality of bus drivers: Between health and work"

BACKGROUND: The bus driving job requires technical skills and emotional control. It is important to equalise the displacement needs of the population and the mental health of drivers, who are subject to the emotional condition of passengers.

OBJECTIVE: To describe, under the light of the phenomenological referential of Maurice Merleau Ponty, the meaning of life quality for bus drivers and its contribution to the mental health of these workers.

METHODS: A descriptive study, with the participation of sixteen (16) bus drivers was performed. Data was collected by means of a phenomenological interview with a semi-structured script that included three open questions in the period from April to November 2014. The explored question was: what means life quality for you? The bus drivers answered the questions in their own interview scripts and the data analysis followed the phenomenological method, considering four steps: suspend, intuit, analyze, and describe. The study was approved by the Ethics Committee of UFF/ HUAP no. 506/339.

RESULTS: The quality of life of the bus drivers was threatened by dissatisfaction in terms of the ergonomic condition of the bus in which they work and the professional development by means of better wages.

CONCLUSIONS: Life quality depends on internal and external factors. Family issues are directly linked to professional well-being at work. The improvements identified are the beginning of a dialogue between the employee and the organization, since work relationship does not mean rivalry, but partnership.
\end{abstract}

\section{KEYWORDS: Consciousness; Perception; Health promotion}

Submetido em 18-04-2016

Aceite em 17-06-2016

1 Este artigo foi extraído da dissertação intitulada “O Mundo da Vida de Motoristas de Ônibus: Estudo Descritivo" (2015), apresentado no I Encontro Internacional Inovação no Ensino na Saúde e Enfermagem.

2 Psicóloga; Doutoranda pelo Programa de Pós-Graduação em Ciências do Cuidado da Saúde da Universidade Federal Fluminense; Mestre em Cuidado em Saúde; Pós-Graduada no Curso de Especialização Psicossomática e Cuidados Com O Corpo pela Universidade Federal Fluminense; Niterói, RJ, Brasil, vanessagilpsicologa@hotmail.com 3 Enfermeira; Filósofa; Psicóloga; Professora associada IV da Universidade Federal Fluminense; Doutora em Psicologia Social pela Universidade Estadual do Rio de Janeiro; Doutora em Enfermagem pela Universidade Federal do Rio de Janeiro; Niterói, RJ, Brasil, roserosauff@gmail.com

4 Pós-Doutora pela Universidade do Estado do Rio de Janeiro; Doutora em Enfermagem pela Universidade Federal do Rio de Janeiro; Professora Associada III na Universidade Federal Fluminense; Docente na Escola de Enfermagem Aurora de Afonso Costa, Niterói, RJ, Brasil, elianeramos.uff@gmail.com

5 Doutorando em Ciências do Cuidado na Saúde na Universidade Federal Fluminense; Especialista em Enfermagem do Trabalho; Presidente do Centro de Estudos do Hospital Estadual Getúlio Vargas; Enfermeiro no Hospital Federal de Bonsucesso, Rio de Janeiro - RJ, Brasil, m.andradesilva1@gmail.com

Citação: Alcantara, V., Silva, R., Pereira, E., \& Silva, M. (2016). O fenômeno qualidade de vida a favor da saúde mental de motorista de ônibus. Revista Portuguesa de Enfermagem de Saúde Mental (Spe. 4), 101-106. 


\section{INTRODUÇÃO}

A qualidade de vida (QV) é multifatorial (Ribeiro, Cotta, e Ribeiro, 2012) e pode ser definida como o grau de prazer e realização pessoal na vida de um indivíduo. Para um elevado nível de QV, devem ser atendidas,minimamente, as necessidades básicas de uma pessoa. As condições laborais e o estilo de vida contribuem sobremaneira para a promoção ou não da $\mathrm{QV}$, influenciando no bem-estar físico e emocional dos indivíduos.

Pode-se afirmar que a saúde física dos trabalhadores é afetada pela atividade laboral. Em estudos de diferentes países, há convergência quanto aos problemas de saúde mais frequentes nessa população: distúrbios osteoarticulares, doenças cardiovasculares, cânceres, distúrbios sensoriais e digestivos, problemas mentais (Thierry, Chouanière, \& Aubry, 2008).

A oportunidade de dar voz aos motoristas foi uma tentativa de superação da carga emocional negativa vivenciada dia a dia por eles. Para que o sujeito se mostre de forma original e sensível, é necessário que a comunicação se estabeleça de maneira a enunciar uma fala falante, isto é, considerando os significados psíquicos atrelados ao discurso. É por meio da fala que se consegue estabelecer novas possibilidades, relações mais abertas ao diálogo e à discussão franca de problemas nas relações. Os trabalhadores do transporte coletivo urbano são frequentemente vítimas de condições precárias de trabalho e, consequentemente, de problemas de saúde associados à atividade laboral (Assunção e Silva, 2013). O referencial teórico utilizado é a fenomenologia de Merleau Ponty, que é uma filosofia transcendental que coloca em suspensoatos e crenças para compreender as afirmações da atitude natural. É também uma filosofia para a qual o mundo está sempre "ali", antes da reflexão, como uma presença inalienável, e cujo esforço consiste em reencontrar este contato ingênuo com o mundo, para lhe dar, enfim, um estatuto filosófico. É a tentativa de uma descrição direta de nossa experiência tal como ela é e sem nenhuma deferência à sua gênese psicológica e às explicações causais (Merleau-Ponty, 2011).

A busca de qualidade de vida para o profissional em análise vem ao encontro da própria necessidade de solidez da mobilidade urbana, que pode ser definida como a capacidade de deslocamento das pessoas e de bens nas cidades, cujas variáveis são tão complexas quanto as variáveis que constituem a própria cidade (Kneib, 2012).
Portanto, o objetivo deste estudo édescrever o significado de qualidade de vida para os motoristas de ônibus e contribuir para a saúde mental destes trabalhadores, pois as condições laborativas podem influenciar a qualidade de vida que é bem-estar físico, emocional e psicológico integrados.

\section{METODOLOGIA}

Estudo descritivo e qualitativo, realizado na zona leste do estado do Rio de Janeiro, de abordagem fenomenológica. Possui como principal característica a análise do fenômeno; epor "fenômeno"Merleau-Ponty se refere àquilo que aparece na correlação intencional $\neg-$ realidade-experiência percebida por alguém.

$\mathrm{O}$ método fenomenológico transcende a dualidade corpo e mente. Merleau-Ponty considera que o estudo da experiência não é um ato psíquico, mas de percepção, de significado ao que vivemos; percepção é o campo onde se fundem sujeito e objeto ancorados no mundo. O sentir e a percepção sãoa ligação fundamental com o mundo e o fio condutor da existência humana (Silva, 2011). É a partir da sensação do mundo que o percebemos como mundo externo a nós. O mundo fenomenológico não é o ser puro, mas o sentido que transparece na intersecção entre as experiências do sujeito, e com as do outro, pela engrenagem de umas nas outras. Ele é, portanto, inseparável da subjetividade e da intersubjetividade que formam sua unidade pela retomada das experiências passadas em presentes, da experiência do outro na do sujeito (Merleau-Ponty, 2011).

Para o filósofo francês, não há verdade absoluta - essa redução impediria o desvelamento do significado feito a partir da experiência individual.O pesquisador descreve e apreende com quem já viveu ou vive a experiência sobre a qual ele quer aprimorar seus conhecimentos; toda consciência é, em algum grau, consciência perceptiva. Se o sujeito pudesse desenvolver todos os pressupostos daquilo que chama de minharazão ou minhas ideias, sempre encontraria experiências que não foram explicitadas, contribuições maciças do passado e do presente, toda uma "história sedimentada" que não concerne apenas à gênese de pensamento, mas determina seu sentido (Merleau-Ponty, 2011).

A pesquisa foi aprovada pelo Comitê de ética e pesquisa da Faculdade de Medicina da Universidade Federal Fluminense/FM/UFF/HU, sendo aprovado sob o CAAE $n^{\circ}$ 19593513.2.0000.5243. 
Os critérios de inclusão foram estabelecidos a partir da política da empresa: profissionais com mais de um ano no cargo, acima de 22 anos, que assinaram Termo de Consentimento Livre e Esclarecido (TCLE). Participaram desta pesquisa 16 profissionais.A proposta do estudo foi apresenta aos participantes, bem como a leitura e a explicação do TCLE, a fim de orientar sobre possíveis questionamentos. Tudo transcorreu de acordo com as especificações éticas e legais da Resolução CNS/N 466/2012 do Ministério da Saúde do Brasil, que regulamenta a pesquisa com seres humanos no país.

Excluíram-se os motoristas que não assinaram o TCLE que possuíam menos de um ano na profissão ouque ficaram afastados de suas atividades por mais de dois anos devido a tratamentos de saúde até a data das entrevistas. As entrevistas foram realizadas entre os meses de abril e novembro de 2014 com 16 motoristas na sala de reunião da garagem de ônibus, localizada no setor de operações. Não houve tempo estipulado para duração, fato que enriqueceu a experiência do encontro. A pergunta norteadora foi: o que é para você qualidade de vida? Após a coleta de dados realizou-se a etapa metodológica da categorização dos dados à luz do método fenomenológico. Os roteiros de entrevistas foram lidos na íntegra e revisados para serem extraídas declarações significativas. Depois de repetidas leituras, formulou-se o significado a fim de articular o insight psicológico em cada uma das unidades de significado (Minayo, 2012). Os roteiros foram separados por aproximação de significados descritos pelos motoristas de ônibus.

Após esta etapa, foi realizada a síntese de todas as unidades de sentido transformadas. Para que houvesse uma declaração consistente, os profissionais escreveram no roteiro suas percepções. Os roteiros foram enumerados de 01 a 16, correspondendo à ordem de leitura. A enumeração teve como fim preservar a identidade do sujeito participante na análise dos dados.

\section{Resultados}

Emergiram três categorias: "a saúde do motorista de ônibus ameaçada pelo desconforto no trabalho"“aimportância da profissão" e "a qualidade de vida é viver em família”.

Na primeira categoria - "a saúde do motorista de ônibus ameaçada pelo desconforto no trabalho" - foi possível compreender a importância da equalização entre as condições de trabalho na direção do ônibus e o relacionamento interpessoal com os clientes.
Para os motoristas de ônibus desta pesquisa, a qualidade de vida foi ameaçada pela insatisfaçãocom as condições ergonômicas dos ônibus em que trabalham. $\mathrm{O}$ interesse por melhores salários também foi evidenciado nas falas a seguir:

Deveria melhorar o respeito no setor de trabalho, como a condição dos bancos dos motoristas que é muito deficiente. E o calor: poderiam dar um conforto para o motorista que começa e termina as viagens (Motorista 02). Condição de trabalho dos coletivos, melhores salários para todos. Maior empenho de toda classe e maior empenho das autoridades competentes, inclusive do sindicato dos rodoviários (Motorista 05).

Sabe-se que o estresse no trânsito altera o comportamento de clientes e dos profissionais.A educação sobre as rodas se esvai quando o tempo é curto e o atraso é inevitável.Os ônibus que servem a cidade transportam, além de vidas humanas, histórias, conversas, expectativas. $\mathrm{O}$ inconsciente do motorista articula-se enquanto trabalha, viaja com ele tentando significar situações, sentimentos vividos no cotidiano laboral.

A segunda categoria, intitulada "aimportância da profissão", correspondeu ao valor dado pelos motoristas de ônibus participantes à profissão. Elesconsideram que qualidade de vida também é a oportunidade de exercer a atividade que gostam, como evidenciam as falas abaixo: Trabalhar como motorista de ônibus é uma profissão boa. Você conhece pessoas todos os dias, o salário não é tão ruim assim. Como todo trabalho, tem o seu lado positivo e negativo. O lado negativo é o trânsito. Às vezes aparecem passageiros abusados, motoristas estressados, porém o mais importante nesta profissão é cuidado, pois você trabalha com vidas (Motorista 07).

Ser motorista é movimentar a história em geral, pois sem essa função, o país para. E quando se faz com amor, uno o útil ao agradável, e torna minha vida bem melhor (Motorista 08).

A satisfação no trabalho é base para a qualidade de serviços e de vida. Para isso, são necessários investimentos em vários níveis. Novas tecnologias foram contratadas para maior conforto e eficácia do trabalho, e os ônibus trocados a fim de promover maior qualidade ao longo da jornada de trabalho. Ações como estas são tomadas constantemente para que o trabalhador tenha condições de terminar sua atividade sem comprometer sua saúde física e mental. Além disso, continuar satisfeito com sua profissão. 
Na categoria "qualidade de vida é viver em família”, os motoristas explicitaram a satisfação de recorrer à família como ponto de equilíbrio para vencer as intempéries do dia a dia:

É tudo aquilo que envolve uma vida saudável e tranquila. Um bom salário, um bom relacionamento familiar, um bom convívio com a sociedade, ter horas de lazer constantes(Motorista 11).

É tudo aquilo que gera frutos e que deixa saudades, no que se realiza: casar, ter filhos, etc.(Motorista 13).

Qualidade de vida para mim é estar feliz com saúde e com sua família; o resto você corre atrás(Motorista 15). O equilíbrio familiar está vinculado ao processo de trabalho do motorista de ônibus. Afinal, sua atenção concentrada na direção e nos agentes externos depende da mente tranquila. Conflitos em casa interferem na concentração do profissional que, enquanto dirige, traz à memória suas angustias e insatisfações. O conflito com o outro é um sofrimento que ganha força no silêncio do fazer solitário que é dirigir.

\section{DISCUSSÃO}

A fenomenologia pode ser definida como a filosofia vivenciada (Dartigues, 2008). É o estudo das essências, e todos os problemasresumem-se em defini-las: a essência da percepção, a essência da consciência (MerleauPonty, 2011). Ela é um referencial teórico, bem como metodológico.O fenômeno é o desvelar da essência do pensamento para os motoristas de ônibus. Fenômeno de qualidade de vida é um conjunto de melhorias a partir do prisma de suas falas sobre a sua atividade,sem a rigidez de preconceitos. A percepção do espaço não é uma classe particular de "estados de consciência" ou de atos, e suas modalidades exprimem sempre a vida total do sujeito, a energia com a qual ele tende para um futuro por meio de seu corpo e de seu mundo (MerleauPonty, 2011).

O trabalho, como direito fundamental do ser humano, deve ser realizado em condições que contribuam para uma melhor qualidade de vida, no intuito de garantir a integridade física e mental ao trabalhador (Bendassolli e Sobol, 2011).

A atividade do motorista de ônibus exige equilíbrio entre o corpo e o psiquismo. São necessárias intervenções garantindo o cuidado ao sujeito motorista. A promoção de saúde por meio de melhoria nosônibus é o passo inicial que a empresa pode realizar para garantir o conforto do trabalhador.
O ajuste dos bancos, respeitando o tamanho e peso do motorista, torna-se importante fator de dimensionamento de sua qualidade de vida no trabalho. O salário e as condições de trabalho estão em constante questionamento pelos próprios trabalhadores, que sempre buscam escalas de trabalho que os possibilitem fazer horas extras, turismos no fim de semana a fim de aumentar a sua renda. A empresa em questão possui preocupação acentuada com este problema, pois o período de descanso é imprescindível para o profissional e para a mobilidade urbana. Para os motoristas, o salário está diretamente ligado à valorização da atividade.

A partir das considerações dos motoristas descritas acima, pode-se afirmar que os gestores devem conhecer os quesitos que geram insatisfação dos funcionários. Em seguida, propiciar ao trabalhador uma abertura para a expressão dos seus recursos internos -autovalorização, satisfação e realização pessoal -; bem como externo facilitando a adaptação do trabalhador à instituição por meio de boas condições de trabalho e infraestrutura, melhores salários, promoções e plano de carreira.

A percepção de sua função na sociedade é o ponto principal que define a maneira de conduzir a vida,o trabalho, em cada modulação gestual que o trabalhador põe em jogo para realizar a tarefa que ele se engaja pelas prescrições da organização. Desse modo, encontra-se na atividade do motorista de ônibus uma pluralidade de sentidos em função das múltiplas forças em luta na sua existência pelos mundos em que habita. É essa pluralidade de forças e lutas que interessam na atividade do motorista. O que é apenas vivido é ambivalente: existem em mim sentimentos aos quais não dou nome e também felicidades falsas em que não estou por inteiro. Entre a ilusão e a percepção, a diferença é intrínseca, e a verdade da percepção só pode ser lida nela mesma (Silva, Keller, \& Coelho, 2013).

A família é a primeira sociedade do sujeito. Seus membros estão unidos por laços consanguíneos de adoção, interesse e/ou afetividade. Ela tem identidade própria, possui e transmite crenças, valores e conhecimentos comuns influenciados por sua cultura e nível socioeconômico. As famílias têm direitos e responsabilidades. Residem em um determinado ambiente em interação com outras pessoas e familiares em diversos níveis de aproximação, definem objetivos e promovem meios para o crescimento, desenvolvimento, saúde e bem-estar de seus membros (Silva, Pereira, Santo, e Silva, 2008). 
Este estudo, subsidiado pela fenomenologia, possibilitou compreender o fazer sob a percepção do motorista de ônibus. Os resultados desta pesquisa nas categorias apontaram para a relevância da fenomenologia ao desvelar o fenômeno da percepção em contraponto à significação da profissão, das relações com os clientes que, em fenomenologia, podem ser definidas como a relação do mundo da vida com o mundo dinâmico, a condição de ir e vir.

Pela valorização do sujeito motorista de ônibus, o estudo possibilita a reflexão dos profissionais das áreas de enfermagem enquanto educadores em saúde, podendo inserir-se no contexto organizacional com programas de controle de peso, da pressão arterial (PA), prevenção de doenças ocupacionais e acidentes. A inserção do enfermeiro neste contexto contribuiria para o controle de ausências ao trabalho (absenteísmo) e também agravos de longa duração.

Quanto aos psicólogos, sugerem-se programas de treinamentos motivacionais, destacando a importância da profissão, e ações estratégicas em saúde mental, permitindo aos profissionais a superação de questões estressoras.

\section{CONCLUSÃO}

Destaca-se que a pesquisa fenomenológica propiciou o mergulho no mundo vivido pelos profissionais do volante, permitindo a descrição do que para eles é qualidade de vida. Os sentidos revelados por eles nesta pesquisa direcionam para a renovação do pensamento organizacional e abertura de novos horizontes para diferentes modos de escuta, ensino eeducação em saúde.

Sugerem-se mais estímulos a programas de promoção de saúde ao trabalhador para prevenção de sintomas ocupacionais. O motorista é a força motriz para o serviço do transporte eficaz nas cidades. A manutenção de bem-estar é multifatorial, porém é de suma importância lembrar que os motoristas de ônibus necessitam de condições positivas para circular pela cidade diariamente.

A qualidade de vida depende de fatores internos e externos aos motoristas. As melhorias apontadas são o início de um diálogo entre o trabalhador e a organização, pois a relação de trabalho não é de rivalidade, mas de parceria.

\section{IMPLICAÇÕES PARA A PRÁTICA CLÍNICA}

Pela valorização do sujeito motorista de ônibus o estudo possibilita a reflexão dos profissionais das áreas de Enfermagem que atendem na própria organização o motorista de ônibus quando a saúde lhe falta, sugere se ao enfermeiro encaminhar o motorista de ônibus aos Recursos Humanos quando o discurso dele transcender ao sintoma observado e aos profissionais de Psicologia como um exercício de reflexão nos Recursos Humanos da organização, que atrás do volante existe um ser humano demandando atenção, é necessário que os Recursos Humanos lhes permitam falar de seus anseios, angustias expectativas e estresses. Sugere-se que mais estudos sobre o tema sejam produzidos a fim de que possa ser superada a invisibilidade da profissão diante da sociedade e promover ações estratégicas para a saúde mental dos motoristas de ônibus.

\section{REFERÊNCIAS BIBLIOGRÁFICAS}

Assunção, A. A., e Silva, L. S. (2013). Working conditions on public buses and common mental disorders among drivers and fare collectors: Greater Metropolitan Belo Horizonte, Minas Gerais State, Brazil, 2012. Cadernos de Saúde Pública, 29, 2473-2486.

Bendassolli, P., e Sobol, L. A. P. (2011). Clínicas do trabalho: Novas perspectivas para compreensão do trabalho na atualidade. São Paulo: Atlas.

Dartigues, A. (2008). O que é fenomenologia? (10 ed.). São Paulo: Centauro.

Kneib, E. C. (2012). Mobilidade urbana e qualidade de vida: Do panorama geral ao caso de Goiânia. Revista Universidade Federal de Goiás, 3(12), 71-78.

Merleau-Ponty, M. (2011). Fenomenologia da percepção ( $4^{\mathrm{a}}$ ed.). São Paulo: Martins Fontes.

Minayo, M. C. S. (2012). Análise qualitativa: Teoria, passos e fidedignidade. Ciência \& Saúde Coletiva, 17(3), 621-626.

Ribeiro, A. G., Cotta, R. M. M., e Ribeiro, S. M. R. (2012). A promoção da saúde e a prevenção integrada dos fatores de risco para doenças cardiovasculares. Ciência \& Saúde Coletiva, 17(1), 7-17. 
Silva, A. A. (2011). O cuidado de si do/a profissional de enfermagem em saúde mental (Dissertação de Mestrado). Rio Grande do Sul: Universidade Federal de Santa Maria.

Silva, R. M. C. R. A., Pereira, E. R, Santo F. H. E., e Silva M. A. (2008). Cultura, saúde e enfermagem: O saber, o direito e o fazer crítico-humano. Revista Eletrônica Enfermagem, 10(4), 1165-1171.
Silva, A. M. B., Keller, B., e Coelho, R. W. (2013). Associação entre pressão arterial e estresse percebido em motoristas de ônibus. Journal of the Health Sciences Institute, 31(1), 75-78.

Thierry, S., Chouanière, D., \& Aubry, C. (2008). Conduite et santé: Une revue de la littérature. Documental Medical Travail,113, 45-63.

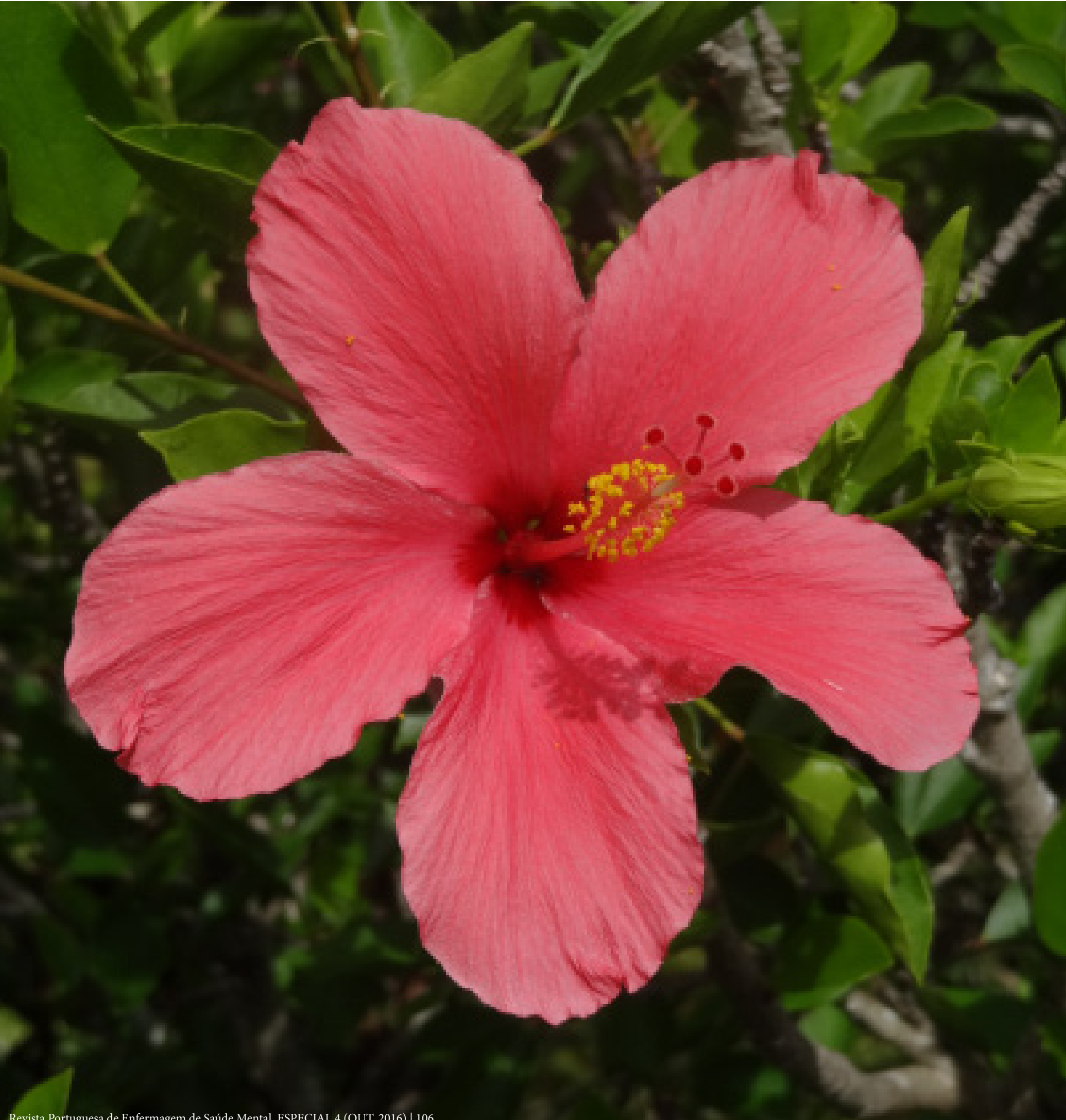

